\title{
Propuestas de gobernanza ambiental en cuencas hidrográficas
}

\section{Environmental governance initiatives in hydrographical basins}

\author{
Ruelas-Monjardín, Laura y Ana C. Travieso-Bello (eds.) (2015), \\ BASES PARA LA CONSTRUCCIÓN DE UN MODELO DE GOBERNANZA. LA CUENCA \\ del río Nautla, El Colegio de Veracruz-Editora de Gobierno, \\ XALAPA, 22 I PP., ISBN 978-607-96800-0-8.
}

México posee una gran diversidad de sistemas naturales y actividades socioeconómicas, cuyas características responden, entre otros factores, a la existencia de agua. Conforme a la Comisión Nacional para el Conocimiento y Uso de la Biodiversidad, alrededor de 56\% del país es árido y semiárido, 37\% subhúmedo y, sólo 7\%, húmedo (Conabio, 1998), es decir, la distribución hídrica es dispar y sin duda es determinante en la construcción del territorio. En el momento en que la existencia de agua es traducida en términos de la necesidad humana (usualmente de corto plazo) se hace patente un escenario de competencia por el acceso a un recurso y el aprovechamiento de éste; ello, en el contexto de una visión "economicista" (Aragón, 2013), además de un manejo poco eficiente, por parte de los diferentes sectores de la sociedad. Se conforma de esa manera una problemática compleja que afecta no sólo el uso sostenible del vital líquido sino el propio desarrollo nacional.

El libro Bases para la construcción de un modelo de gobernanza. La cuenca del rio Nautla da cuenta de los grandes desafíos para la gobernanza de una de las regiones más ricas y diversas en términos bióticos, así como en actividades socioeconómicas del estado de Veracruz: la cuenca del río Nautla. La obra está integrada por siete investigaciones que resaltan el interés por buscar explicaciones y respuestas a la compleja problemática de esa región, por muchos años tratada desde una óptica de provecho económico que dio como resultado un uso irreflexivo de sus recursos, al grado de que hoy el sistema natural y el social se encuentran en riesgo.

Pese a algunos loables intentos, desde la academia, por reconocer la problemática, no había ocurrido una iniciativa suficientemente ambiciosa para comprenderla en su integralidad. Hasta muy recientemente, cuando desde el Colegio de Veracruz y la Universidad Veracruzana, la 
región del Nautla empezó a recibir la atención necesaria, que se cristaliza con este libro.

Los capítulos de la obra describen y estudian las condiciones de la cuenca del Nautla desde diferentes enfoques disciplinarios, mismos que, en una primera aproximación, se ubican en las ciencias de lo natural y lo social. La lectura de cada trabajo permite constatar que ambas aproximaciones convergen de manera recurrente, ofreciéndonos algunas reflexiones, a las que enseguida me referiré.

La obra en particular permite dilucidar que el manejo de la cuenca ha sido deficiente, lo cual obedece no únicamente a las acciones de los actores en su interior; responde, tal vez de manera más decisiva, al impacto de actores externos, cuyas decisiones, acciones u omisiones no han sido, en muchos casos, benéficas para su equilibrio y buen mantenimiento. Por otra parte, los temas preocupantes en el área demandan aproximaciones multidisciplinarias para encontrar explicaciones y plantear alternativas de solución viables.

Condición necesaria para reunir propuestas que mejoren el estado de la cuenca, es el reconocimiento de sus características físicas, socioeconómicas, políticas e institucionales, entre otras. Este es el reto que encaran los autores de la obra. Así, Hugo Riemann analiza el estado de los sistemas naturales del área de estudio y los factores que provocan mayor impacto en su conservación. Su conclusión no es halagüeña, pues asevera que la envidiable riqueza de componentes bióticos contrasta con el panorama de deterioro que exhibe la región, resultado de la transformación de sus sistemas naturales a sistemas de producción que responden a economías de mercado. Ante este escenario, plantea que las alternativas de conservación y manejo deben involucrar a la población en proyectos de beneficio social que no sólo recuperen y actualicen el manejo tradicional de sus recursos, sino que también sean capaces de poner en práctica novedosas formas de aprovechamiento a largo plazo.

Ana Cecilia Travieso-Bello e Isidro Hernández Salazar, por su parte, advierten que en una demarcación concreta como el municipio de Perote, en la parte más alta de la cuenca, la vegetación natural ha sufrido procesos de deforestación. Asimismo, han ocurrido cambios de uso del suelo, tanto por prácticas agroproductivas como por el aumento de la población. En ese sentido, la legislación y las políticas implementadas en México y en la entidad veracruzana no han frenado estos procesos. Por tanto, para estos autores, el reto es desarrollar la gobernanza ambiental que promueva la participación de todos los actores involucrados, con conocimientos y poder para la adopción de decisiones sobre los usos del sistema natural, con apego a la normatividad y una visión de desarrollo sustentable. 
Selene Janitzio Pérez Córdova y Ana Cecilia Travieso-Bello centran su estudio en el municipio de Nautla y advierten que ahí se suscitan inundaciones recurrentes, que ubican a más de la mitad del territorio en categoría de peligro alto o muy alto, y que afecta a más de $80 \%$ de la población. Pese a que este aspecto es conocido, se opta por una gestión correctiva en lugar de una con carácter prospectivo para evitar o reducir el riesgo. Aseguran que el entendimiento del problema permite promover la participación informada de todos los actores y propiciar que sean conscientes de sus consecuencias ambientales, sociales y económicas. También nos recuerdan que la participación es esencial para el fortalecimiento del andamiaje institucional necesario para proponer esquemas de planeación basados en los principios del desarrollo sustentable.

Otro de los autores de la obra, Ricardo Santes-Álvarez, asevera que el deterioro ambiental y los problemas sociales que surgen en la cuenca del Nautla determinan la calidad de su gobernación. Los retos que surgen tienen sustento en tres aspectos de atención imprescindible: 1 . Un diseño institucional centralista y generalizador que excluye capacidades, necesidades y demandas de los actores locales. 2. Una gestión productivista que percibe al elemento hídrico como bien económico solamente, olvidando que es, antes que todo, un derecho humano y un bien público. 3. Un nudo sociopolítico, donde los actores con mayor capacidad de influencia determinan la viabilidad de los recursos naturales y el futuro de las comunidades locales. Por lo anterior, un arreglo alternativo para la gobernación del área es factible, si se adopta una concepción que atienda las cuestiones sociales y ambientales en un marco de integralidad y sustentabilidad. De ahí que la idea de paisaje fluvial sea una alternativa.

El trabajo realizado por Alonso Irán Sánchez Hernández, Martha Elena Nava Tablada y Laura C. Ruelas-Monjardín es un detallado estudio del Consejo de Cuenca de los ríos Tuxpan al Jamapa (CCTJ), donde se incluye la del río Nautla. En el mismo, los autores ofrecen noticias poco optimistas, toda vez que sus pesquisas determinan que existe escasa representatividad y participación de actores sociales en la toma de decisiones sobre saneamiento del agua. Por tal motivo, el Consejo es poco exitoso en la construcción de procesos efectivos de gobernanza: es apenas una instancia de carácter consultivo que tiene acotado su margen de acción. Aspecto inquietante es que las reuniones de Consejo, que deben celebrarse periódicamente, poco o ningún interés les merecen a los representantes gubernamentales federales y estatales, pues su ausentismo es patente. Peor aún es que a dichas reuniones no asisten representantes municipales. En esto último, aventuro decir que la ausencia de los gobiernos locales quizá se deba a su escasa o nula relevancia en la mesa de discusiones. En todo caso, el asunto no sólo refleja el desinterés gubernamental por atender el 
tema del agua, sino a comprometerse con los objetivos del desarrollo regional y nacional. Sobre todo, el desinterés por atender las necesidades socioambientales de las diferentes cuencas.

La experiencia del CCTJ contrasta con una concepción ideal, tal como se describe en el estudio comparativo con el Consejo de la Cuenca del Fraser, en Canadá (Fraser Basin Council), que realiza Laura C. RuelasMonjardín. Esto es, que dichas instancias significan un cambio en el papel del gobierno, de controlador a facilitador de las decisiones locales. En ese sentido, una distinción clave para su funcionamiento es la colaboración de grupos de interés y funcionarios, así como el suministro de presupuesto suficiente y la delegación de la autoridad en la toma de decisiones. Evidentemente, el modelo choca con el caso mexicano, donde el gobierno federal no cambia su papel de controlador casi absoluto. Por tanto, no hay algún tipo de descentralización con desconcentración, delegación, ni mucho menos con devolución.

$\mathrm{Si}$, como se anota en el capítulo de Ruelas-Monjardín, "el manejo del agua debe hacerse al nivel más local posible", (p. 87) donde se originan los asuntos relativos a su uso o abuso, pero principalmente donde los individuos reconocen su papel en la producción, y solución, de los problemas, es patente que el modelo mexicano debe reformarse. En el caso del CCTJ, la institución central fuerte necesita de instituciones locales fuertes, por lo que el diseño arriba-abajo debe transitar a uno más equilibrado donde la agenda sea conformada tomando en cuenta el flujo abajo-arriba. Todo un reto para los modos tradicionales de tomar decisiones en México, lo que lleva a cuestionar sobre el futuro posible para la cuenca.

Permitiéndome un ejercicio de reflexión sobre cualquier alternativa de solución a los problemas de la región del Nautla aquí comentados, considero pertinente insistir en la relevancia del factor externo, esto es, el conjunto de directivas y medidas que se gestan fuera de la cuenca y que inciden en su devenir. Si no se repara en esta vertiente, difícilmente cristalizará cualquier propuesta que conduzca a la solución de los retos que enfrenta la región en su conjunto. No es fácil obviar la visión dominante del quehacer público en México, de fuerte connotación centralista como lo recogen varias contribuciones en el libro. Pese a intentonas porque esta tendencia cambie o al menos sea matizada, la tradición es más poderosa que la reforma. De ahí que el marco institucional vigente revela la perspectiva del desarrollo nacional, que condiciona políticas, estrategias y medidas para la administración del Nautla, así como de todas las regiones de cuencas hidrográficas del país.

El crecimiento económico ha sido el objetivo principal de las políticas del agua, lo que ha puesto en las márgenes los objetivos ambientales y sociales. Es ilustrativo de esta situación el procedimiento que sigue la 
Comisión Nacional del Agua, que otorga concesiones y asignaciones a los usuarios registrados para explotar las fuentes, pero presta poca atención a sus condiciones reales, incluso a sabiendas que está concediendo más cuota que la que realmente existe. Otro, es el hecho que el estado subsidia el costo de la energía que necesitan algunos usuarios para obtener el líquido.

Es justificada la preocupación de que los recursos hídricos se ubican heterogéneamente en el territorio nacional, y de ahí lo difícil de su acceso en muchos sitios. Pero también se justifica la aseveración que la gestión de esos recursos es deficiente, y su distribución entre los distintos sectores de la sociedad es desigual. De ahí que, una lección adicional que nos ofrece la obra coordinada por Ruelas-Monjardín y Travieso-Bello es que los objetivos institucionales en torno al tema del agua en México fallan en reflejar las diferentes condiciones geográficas, así como las dispares dinámicas socioeconómicas. Puede decirse que Veracruz y los demás estados que se ubican en la región sur-sureste no tienen problemas de disponibilidad del líquido; sin embargo, es claro que la mayor parte del país presenta condiciones climáticas rigurosas, hasta la aridez, y que se padece escasez como resultado de gestiones deficientes. Por ello, es inviable instrumentar políticas para el manejo del agua que se desentiendan de su desigual distribución, limitada disponibilidad y mal manejo.

El discurso en torno al agua es variopinto: hay quienes la consideran un bien económico y por tanto, susceptible de explotación sin freno, mientras que otros la consideran un bien esencial para la vida, y por tanto, algo que debe preservarse y manejarse ponderando los intereses de la sociedad en general. Pero del discurso a la acción hay un largo trecho. Dan muestra de ello dos de los más relevantes instrumentos de política pública relacionados con este tema: el Plan Nacional de Desarrollo 20132018 (PND) y el Programa Nacional Hídrico 2014-2018 (PNH). El primero destaca que el país tiene gran diversidad de recursos, suficientes para lograr el crecimiento económico; sin embargo, el gran reto es aumentar la productividad; en consecuencia, a través del objetivo de México Próspero es necesario lograr estabilidad económica y generar igualdad de oportunidades. Esto último, considerando que la infraestructura adecuada y el acceso a insumos estratégicos promueven la competencia y permiten mayores flujos de capital y conocimiento hacia los individuos y las empresas (Gobierno de la República, 2013: 22).

Llama la atención la concepción de "sustentabilidad" que defiende el PND: incluye el manejo responsable de los recursos hídricos, el aumento de la cobertura de los servicios de agua potable, alcantarillado y saneamiento, así como la infraestructura hidroagrícola y de control de inundaciones (Gobierno de la Republica, 2013: 86). Con lo anterior, se avizora 
la percepción prevaleciente sobre el agua, consistente en ser un objeto de uso. "Responsable" sí, en la medida que no comprometa la meta del crecimiento, porque en un esquema de toma de decisión, lo importante es lo segundo, como queda expuesto con mayor claridad en la sección de Líneas de Acción, donde se defiende la idea de "crecimiento verde incluyente y facilitador” (páginas 134-135 del PND), que poco enaltece el interés por preservar y conservar los recursos naturales en las diferentes regiones de México. En similar sentido se pronuncia el PNH, el cual presenta dos objetivos que tienen que ver con la disponibilidad de líquido para fines económicos y domésticos (Semarnat, 2014): 1. Fortalecer el reparto de agua y el acceso a servicios básicos, mediante el cuidado y el aumento de la infraestructura necesaria; y 2. Garantizar la disponibilidad de agua para el agro-producción y otras actividades económicas (Semarnat, 2014: 69-70 y 73-74).

Las reflexiones que surgen, luego de la lectura del libro coordinado por Ruelas-Monjardín y Travieso-Bello, brindan orientaciones útiles para aspirar a una reforma exitosa a los modos imperantes en la gobernación de la cuenca del Nautla. Urge una racionalidad alternativa que ponga por delante objetivos sociales y de sustentabilidad ambiental. Aunque los capítulos de la obra parecen coincidir en que la prioridad nacional es poner las políticas de gestión del agua al servicio de la producción y las demás actividades económicas, dejando otras necesidades en los márgenes, también parecen coincidir en la urgencia de aplicar los medios necesarios (en lo que respecta a las leyes, políticas y organizaciones) para adoptar una gestión responsable y sostenible de los recursos hídricos.

Una aduana insalvable en este propósito es fortalecer la capacidad de interlocución de los actores sociales; sobre todo, aquellos que son directamente afectados o beneficiados por las decisiones de política pública. La alternativa implica transitar de una visión de gestión arriba-abajo a una que vaya de la base hacia la cúspide, mediante la promoción de una sociedad civil fortalecida. Y aunque ello no sea labor de un día para otro, el fortalecimiento político de la sociedad civil, que implica la construcción de ciudadanía, es una vía necesaria para aspirar a un futuro mejor.

Concluyo con algunas observaciones de Andreas Klinke, otro de los autores de esta obra, que no sólo avala las reflexiones expresadas, sino que aporta una lección adicional: aun en los escenarios del mundo desarrollado, pretender transitar de la tradición a la reforma es tarea difícil. En efecto, para este autor, cuya aportación trata la gobernación del agua en Los Grandes Lagos, en la frontera Canadá-Estados Unidos, la participación y la deliberación en niveles múltiples son esenciales para una gobernanza del agua en las cuencas; entre otras razones, porque incrementa la legitimidad de las decisiones tomadas y la posibilidad de resol- 
ver los problemas; asimismo, porque fortalece el papel de los individuos como miembros de la comunidad. Sin embargo, advierte que "La institucionalización y posibilidad de un nuevo diseño enfrenta obstáculos, debido a la forma de gobernar de los sistemas políticos tradicionales" (p. 140). Sin discusión, la participación y deliberación multinivel constituyen una propuesta, a la vez que un desafío, que debemos abordar en México. El libro Bases para la construcción de un modelo de gobernanza. La cuenca del río Nautla, devela alternativas que apuntan hacia esa ruta.

\section{Fuentes consultadas}

Aragón García, Victoria (2013), "Agua: la construcción discursiva de un conflicto", Documentos de Trabajo en Sociología Aplicada, Universidad de Murcia, Murcia, <http://revistas.um.es/dtsa/article/ download/154491/147761>, abril de 2016 .

Conabio (Comisión Nacional para el Conocimiento y Uso de la Biodiversidad) (1998), La diversidad biológica de México: Estudio de pais 1998, Conabio, México.

Gobierno de la República (2013), "Plan Nacional de Desarrollo 20132018”, Diario Oficial de la Federación, México, 20 de mayo.

Semarnat (Secretaría de Medio Ambiente y Recursos Naturales) (2014), "Programa Nacional Hídrico 2014-2018”, Diario Oficial de la Federación, México, 8 de abril.

Recibido: 11 de mayo de 2016. Corregido: 29 de julio de 2016. Aceptado: 1 de agosto de 2016.

Ricardo V. Santes-ÁlVAREZ El Colegio de la Frontera Norte

CoRreO-E: RSANTES@COLEF.MX

Ricardo V. Santes-Álvarez. Mexicano. Doctor en análisis y evaluación de procesos políticos y sociales. Doctor Europeus, Universidad Carlos III de Madrid, España. Profesor-investigador en el Departamento de Estudios Urbanos y Medio Ambiente en El Colegio de la Frontera Norte. Sus líneas de investigación son gobernanza ambiental, actuación de instituciones 
formales y sustentabilidad de recursos naturales. Entre sus publicaciones recientes se encuentran: "Aspectos que definen la gobernación del uso de agua en región San Quintín”, en Hugo Riemann (coord.), El agua en la región agricola Camalú-El Rosario, Baja California. Un recurso sobreexplotado con repercusiones sociales y ambientales, RNIU, México, pp. 95-115 (2015); "Gobernanza y medio ambiente: experiencias de actuación institucional en la frontera México-Estados Unidos", en Laura RuelasMonjardín, Ana C. Travieso-Bello y Odilón M. Sánchez (eds.), Gobernanza ambiental. Teoría y práctica para la conservación y uso sustentable de los recursos, Plaza y Valdés-Colver, México, pp. 237-258 (2015); en coautoría: "Intereses económicos y ambientales en un entorno de interdependencia: Sempra Energy, en Baja California”, Sociedad y Ambiente, 1 (7), Colegio de la Frontera Sur, Campeche, pp. 99-116 (2015); "Gobernación del cambio climático en México: expectativas de reformas en el contexto sub-nacional", DRd-Desenvolvimento Regional em debate, 5 (1), Universidade do Contestado, pp. 88-110 (2015); "Instituciones y política en la gobernación de la cuenca del río Nautla”, en Laura Ruelas-Monjardín y Ana C. Travieso-Bello (eds.), Bases para la construcción de un modelo de gobernanza. La cuenca del río Nautla, El Colegio de Veracruz-Editora de Gobierno, Xalapa, pp. 25-54 (2015). 